\title{
Competition of several carbonation reactions in concrete: a parametric study
}

\author{
M. A. Peter ${ }^{\mathrm{a}, 1}$, A. Muntean ${ }^{\mathrm{a}, 2}$, S. A. Meier ${ }^{\mathrm{a}}$ and M. Böhm ${ }^{\mathrm{a}}$ \\ ${ }^{a}$ Centre for Industrial Mathematics, FB 3, University of Bremen, \\ Postfach 330 440, 28334 Bremen, Germany.
}

\begin{abstract}
Carbonation caused by atmospheric carbon dioxide is one of the major physicochemical processes which can compromise the service life of reinforced concrete structures. While the bulk of the carbonation reaction is that of calcium hydroxide, other constituents of the porous matrix can also carbonate and compete with calcium hydroxide for carbon dioxide. Particularly the carbonation of calcium-silicate hydrates and unhydrated constituents are neglected by most authors in carbonation prediction models. In this paper, a mathematical model of carbonation is extended to include additional carbonation and hydration reactions. The competition of the several reactions and their effect on the carbonation depth is investigated by dimensional analysis and numerical simulations. A parameter study emphasises that multiple internal reaction layers appear. Their position and speed essentially depend on the strength of the different reactions. It is also observed that, for a wide range of parameters, the effect of some of the additional reactions on the carbonation depth is small. In particular, a comparison with data from laboratory experiments justifies the neglect of the carbonation of the unhydrated constituents in prediction models.
\end{abstract}

Key words: carbonation, internal reaction layers, diffusion, modelling, finite element analysis

$\overline{1}$ Corresponding author. Tel.: +64 93737599 ext. 83974, fax: +64 9 3737457. Current address: Department of Mathematics, University of Auckland, Private Bag 92019, Auckland 1142, New Zealand.

2 Current address: CASA, Department of Mathematics and Computer Science, Technische Universiteit Eindhoven, P.O. Box 513, 5600 MB Eindhoven, The Netherlands.

E-mail addresses: mpeter@math.auckland.ac.nz (M. A. Peter), a.muntean@tue.nl (A. Muntean), sebam@math.uni-bremen.de (S. A. Meier), mbohm@math.unibremen.de (M. Böhm). 


\section{Introduction}

Steel bars in reinforced concrete are protected from corrosion by the highly alkaline environment inside the concrete $(\mathrm{pH} \approx 13)$. If the $\mathrm{pH}$ decreases in the environment of the reinforcement, this protection ceases and the steel bars can corrode. Consequently, the rusting of the reinforcement usually leads to a severe reduction of the durability of the structure. One of the main processes facilitating the destruction of the protection by alkalinity is carbonation, i.e. the reaction of alkaline constituents of the concrete with atmospheric carbon dioxide to produce carbonates. Detailed surveys and literature accounts on the carbonation problem and related aspects concerning the durability of concrete-based materials can be found, for instance, in $[1,2,3,4,5,6]$ and references therein. A short summary of the carbonation process is as follows: The atmospheric carbon dioxide diffuses through the unsaturated concrete pores, dissolves in the pore water, and then reacts with carbonatable solutes. These are available in the pore solution by dissolution from the solid matrix. The main carbonation reaction is that of calcium hydroxide. It may be described by

$$
\mathrm{CO}_{2}(g \rightarrow a q)+\mathrm{Ca}(\mathrm{OH})_{2}(s \rightarrow a q) \longrightarrow \mathrm{CaCO}_{3}(a q \rightarrow s)+\mathrm{H}_{2} \mathrm{O} .
$$

Once produced, carbonates precipitate quickly to the solid matrix. Experimental evidence (cf. [4], e.g.) suggests that the bulk of the carbonation reaction (1.1) is located on an internal reaction layer of a priori unknown width and position, which gradually progresses into the material (cf. [7, 6], e.g.).

Other constituents in the concrete can also carbonate, particularly calciumsilicate hydrates (C-S-H), which are the major constituents of hydrated cement paste and occur with several stoichiometries, and the (C-S-H)-producing unhydrated phases dicalcium silicate and tricalcium silicate $\left(\mathrm{C}_{2} \mathrm{~S}\right.$ and $\left.\mathrm{C}_{3} \mathrm{~S}\right)$. In this paper, we focus on the carbonation of these constituents. Note, that there are more species like $\mathrm{KOH}, \mathrm{NaOH}, \mathrm{Mg}(\mathrm{OH})_{2}$ and the aluminate phases which may also carbonate. However, we expect their influence on the overall carbonation to be of similar nature but not as strong. We refer to $[1,5,8,9,7]$ for more details on the carbonation of all of these constituents.

Experiments suggest that the C-S-H phases start carbonating as soon as the available calcium hydroxide has been depleted via (1.1), cf. [10], e.g. It is noteworthy that reasonable amounts of calcium hydroxide may still be present in the concrete at this time [11]. At the same time, $\mathrm{C}_{2} \mathrm{~S}$ and $\mathrm{C}_{3} \mathrm{~S}$ react with water to produce calcium hydroxide and $\mathrm{C}-\mathrm{S}-\mathrm{H}$ which is called hydration of concrete. We do not go into detail in what the modelling of the hydration is concerned but rather refer the reader to $[12,13,14,7]$ for fairly detailed descriptions of the involved physicochemical processes and to $[15,16]$ for a presentation of a few qualitative (mathematical) issues concerning some of the existing hydration models. Moreover, it is well-known that the ingress of chlorides and 
sulfates may essentially interact with the carbonation process to result in concrete corrosion [17]. In this work, we concentrate on the carbonation.

The carbonation reactions of the other carbonatable species are usually not as fast as that of calcium hydroxide but are still faster than the hydration reactions in the late stage of hydration considered here. (We consider the hydration process in its final period, i.e. much later than 28 days after the mixing.) However, all of these reactions still compete for carbon dioxide. It is the aim of this paper to qualitatively investigate the competition between the several parallel carbonation reactions in concretes with Ordinary Portland Cement (OPC). We follow the model by Papadakis et al. [7] to account for some remaining hydration reactions and study also the additional competition between hydration and carbonation of unhydrated constituents. This is particularly interesting since many authors neglect all of these aspects when modelling and simulating concrete carbonation, which consequently may lead to an over-estimation of the real carbonation depth. Besides the carbonation models already mentioned above, numerous other models exist taking into account different aspects of the carbonation process, e.g. the recent model of Bary et al. [18]. We refer to [9] for a literature review of known carbonation models. The mathematical model presented here is an extension of the model developed and tested in [19] extensively using ideas found in [7] to include the additional phases.

The main output of our model is the carbonation penetration depth, which indicates how far the reaction layer associated with (1.1) has advanced into the concrete sample at a given time. In $[19,7]$, the dynamics of this layer was investigated for a simplified model. It was shown that the speed and width of the layer is strongly related to the Thiele modulus, a dimensionless number relating the reaction strength to the diffusion of $\mathrm{CO}_{2}$. In the present work, we also investigate the evolution of additional internal layers associated with the respective reactions of the other carbonatable constituents. Our study is based on a nondimensionalisation of the governing system of equations allowing easy comparisons and calculations of the relevant characteristic time scales. In order to focus on the influence of the various carbonation reactions, we make several simplifying assumptions, which are not valid for natural carbonation (uniform water saturation degree, e.g.; see below). Therefore, in the simulations we consider an accelerated test (cf. [7]), for which the state of hydration is fairly certain at the beginning of the test and the level of the $\mathrm{CO}_{2}$ concentration in the carbonation chamber is strongly increased. However, the modelling ideas can also be applied to natural carbonation, cf. [19]. We would also like to point out that some technical details and minor simulation illustrations are omitted in this work. They can be found in the report [20].

An alternative modelling approach of the fast-reaction-slow-diffusion setting, which holds for carbonation, are moving-boundary models. Here, the internal 
reaction layers, which in the present model come out as part of the model output, can be explicitly incorporated in the models. We do not follow this approach, but refer to $[21,6]$ where various conceptually distinct movingboundary models are suggested and investigated for a simplified carbonation setting. We also mention a recent two-scale approach [22] that allows to take into account different spatial and time scales of the process in a more sophisticated manner as well as a new homogenisation approach for chemcial degradation mechanisms in porous media inducing an evolution of the microstructure [23].

The paper is organised as follows: In section 2, for the sake of completeness, we present the chemical reactions that are accounted for in this model. In section 3 , the mathematical model is formulated. Its nondimensionalisation is briefly described in section 4 . There, we also list the relevant dimensionless numbers. The largest part of this paper is section 5. It contains a significant part of our numerical experiments. We particularly study the competition of carbonation and hydration reactions and that between the different carbonation reactions as well as their effect on the penetration curves. We also investigate the effect of changes in the rapidness of the carbonation and hydration reactions and the amount of available carbonatable constituents on the penetration curves and compare them to experimental data from [7]. Finally, we summarise the simulation results and conclusions in section 6 .

\section{Chemical reactions}

It is known that if the hydration reactions are not complete, then some of the unhydrated constituents may carbonate (see [7], e.g.). Consequently, we expect that a special competition between hydration and carbonation reactions may take place. Such a competition does not seem to be too significant in the case of accelerated testing, mainly due to the high hydration degree that is reached by the sample during the period before the accelerated test starts [9]. However, since much more $\mathrm{CO}_{2}$ is available for reaction compared to natural carbonation, the effect might be stronger yet again.

\subsection{Hydration reactions}

The main species to be hydrated are $2 \mathrm{CaO} \cdot \mathrm{SiO}_{2}$ (dicalcium silicate, $\mathrm{C}_{2} \mathrm{~S}$ ) and $3 \mathrm{CaO} \cdot \mathrm{SiO}_{2}$ (tricalcium silicate, $\mathrm{C}_{3} \mathrm{~S}$ ). The products of their hydration are $\mathrm{Ca}(\mathrm{OH})_{2}$ and $\mathrm{C}-\mathrm{S}-\mathrm{H}$. There are at least five different morphologies and several possible stochiometries of C-S-H-phases which grow during the hydration process $[13,12,24,25]$. In our approach, the exact morphology is not relevant, 
and, for definiteness, we restrict ourselves to the stoichiometric combination (3-2-3), i.e. $3 \mathrm{CaO} \cdot 2 \mathrm{SiO}_{2} \cdot 3 \mathrm{H}_{2} \mathrm{O}$, which we denote by $\mathrm{CSH}$ in what follows. Amorphous silica gel and calcium carbonate are usually the end products of carbonation (see [26], [9] and references therein).

The hydration reactions of $\mathrm{C}_{2} \mathrm{~S}$ and $\mathrm{C}_{3} \mathrm{~S}$ are given by

$$
\begin{aligned}
& 2\left(2 \mathrm{CaO} \cdot \mathrm{SiO}_{2}\right)+4 \mathrm{H}_{2} \mathrm{O} \longrightarrow\left(3 \mathrm{CaO} \cdot 2 \mathrm{SiO}_{2} \cdot 3 \mathrm{H}_{2} \mathrm{O}\right)+\mathrm{Ca}(\mathrm{OH})_{2}, \\
& 2\left(3 \mathrm{CaO} \cdot \mathrm{SiO}_{2}\right)+6 \mathrm{H}_{2} \mathrm{O} \longrightarrow\left(3 \mathrm{CaO} \cdot 2 \mathrm{SiO}_{2} \cdot 3 \mathrm{H}_{2} \mathrm{O}\right)+3 \mathrm{Ca}(\mathrm{OH})_{2},
\end{aligned}
$$

respectively $[12,7]$. These reactions are typically associated with the (porous) matrix space or the solid-matrix surface (as opposed to the pore space) at the late stage of hydration considered here. We assume that there is a sufficient amount of water available in the matrix space for the hydration reactions to reach completion.

\subsection{Carbonation reactions}

Aqueous carbon dioxide is consumed by several carbonation reactions. The main carbonation reaction is usually described by

$$
\mathrm{Ca}(\mathrm{OH})_{2}+\mathrm{CO}_{2} \longrightarrow \mathrm{CaCO}_{3}+\mathrm{H}_{2} \mathrm{O} \text {. }
$$

Besides $\mathrm{Ca}(\mathrm{OH})_{2}$, another hydration product, $\mathrm{CSH}$, as well as unhydrated constituents such as $\mathrm{C}_{2} \mathrm{~S}$ and $\mathrm{C}_{3} \mathrm{~S}$ are susceptible to carbonation. By [7, 3], e.g., their carbonation reactions can be described via

$$
\begin{aligned}
& \left(3 \mathrm{CaO} \cdot 2 \mathrm{SiO}_{2} \cdot 3 \mathrm{H}_{2} \mathrm{O}\right)+3 \mathrm{CO}_{2} \longrightarrow\left(3 \mathrm{CaCO}_{3} \cdot 2 \mathrm{SiO}_{2} \cdot 3 \mathrm{H}_{2} \mathrm{O}\right), \\
& \left(2 \mathrm{CaO} \cdot \mathrm{SiO}_{2}\right)+2 \mathrm{CO}_{2}+n \mathrm{H}_{2} \mathrm{O} \longrightarrow\left(\mathrm{SiO}_{2} \cdot n \mathrm{H}_{2} \mathrm{O}\right)+2 \mathrm{CaCO}_{3}, \\
& \left(3 \mathrm{CaO} \cdot \mathrm{SiO}_{2}\right)+3 \mathrm{CO}_{2}+n \mathrm{H}_{2} \mathrm{O} \longrightarrow\left(\mathrm{SiO}_{2} \cdot n \mathrm{H}_{2} \mathrm{O}\right)+3 \mathrm{CaCO}_{3},
\end{aligned}
$$

respectively. The coefficient $n$ represents an arbitrary positive number of moles of water that is conserved through the reactions (2.5) and (2.6). The carbonation reactions (2.5) and (2.6) do not directly affect the alkalinity of the concrete. We may account for this scenario provided the concrete is sufficiently wet and all carbonatable constituents are available to $\mathrm{CO}_{2}$. This can be viewed as a worst-case scenario regarding the impact on the overall carbonation.

\section{Mathematical model}

We focus on a part $\Omega$ of a concrete sample which is exposed to ingress of gaseous $\mathrm{CO}_{2}$ from the exterior (figure 1 ). The domain $\Omega$ is chosen close to the exposed boundary $\Gamma^{\mathrm{R}}$, such that it contains the reaction layers. In the interior 


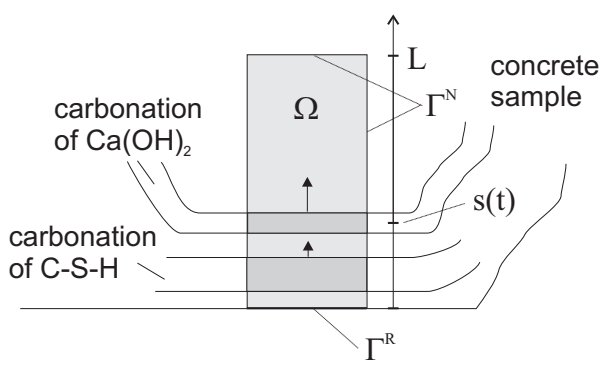

Fig. 1. Schematic view of a concrete sample exhibiting two different carbonation layers. $L$ is the width of the sample, and $s(t)$ is the (main) carbonation depth (defined in (4.5)) which is usually visualised by a phenolphthalein test.

of the sample, $\Omega$ is bounded by $\Gamma^{\mathrm{N}}$ which is chosen such that it is never reached by the reaction layer during the time interval of interest. At this internal boundary, no-flux conditions are prescribed for all active species in the model. Although the model is formulated independently of the space dimension, our numerical simulations only deal with one-dimensional situations. See also [19] for more details.

\subsection{Basic notations}

We introduce some concepts usually needed to describe reactive processes taking place in porous media (see [27], e.g.). The region $\Omega$ is composed of the solid matrix $\Omega^{\mathrm{s}}$ and of the totality of pore voids $\Omega^{\mathrm{p}}$. Furthermore, since the pore space is assumed to be unsaturated and carbonation is a heterogeneous process, $\Omega^{\mathrm{p}}$ can be thought of to be split into $\Omega^{\mathrm{a}}$ (the parts filled with dry air and water vapours) and $\Omega^{\mathrm{w}}$ (the parts filled with liquid water). We denote by the volumetric ratio $\phi:=\left|\Omega^{\mathrm{p}}\right| /|\Omega|$ the concrete porosity and by $\phi^{j}:=$ $\left|\Omega^{j}\right| /\left|\Omega^{\mathrm{p}}\right|$ the air and water fractions, where $j \in\{\mathrm{a}, \mathrm{w}\}$. Cf. [7], the porosity $\phi$ strongly decreases during the initial hydration period. In the late stage of hydration considered here, the change of porosity due to hydration is only very small. It is known that the carbonation of $\mathrm{Ca}(\mathrm{OH})_{2}$ and $\mathrm{C}-\mathrm{S}-\mathrm{H}$ can cause a considerable change of the porosity during lifetime of the concrete structure (see [7]). However, for the present qualitative study we assume that these effects only play a minor role and assume a constant concrete porosity. It is worth noting that the model presented below is conceptually capable of taking into account a time-dependent porosity and we refer to [19] for details on this. Throughout the paper, the space and time variables are denoted by $x$ and $t$, respectively, where $x \in \Omega$ and $t \geq 0$.

We denote the active mass concentrations by $c_{\mathrm{CO}_{2}(g)}\left(\mathrm{CO}_{2}\right.$ in pore air $), c_{\mathrm{CO}_{2}}$ $\left(\mathrm{CO}_{2}\right.$ in pore water $), c_{\mathrm{Ca}(\mathrm{OH})_{2}}\left(\mathrm{Ca}(\mathrm{OH})_{2}\right), c_{\mathrm{CaCO}_{3}}\left(\mathrm{CaCO}_{3}\right), c_{\mathrm{CSH}}(\mathrm{CSH}), c_{\mathrm{C}_{2} \mathrm{~S}}$ $\left(\mathrm{C}_{2} \mathrm{~S}\right)$, and $c_{\mathrm{C}_{3} \mathrm{~S}}\left(\mathrm{C}_{3} \mathrm{~S}\right)$. As the transport of moisture is assumed to play no central role in the present study, we consider a uniform moisture distribution 
throughout the sample.

\subsection{Production terms}

The kinetics of the carbonation and hydration reactions are assumed to be of power-law type. We follow the modelling approaches found in $[7,8,28]$. As in [7], the production terms by hydration are defined as

$$
f_{\mathrm{C}_{2} \mathrm{~S}}^{\text {hydr }}:=C_{\mathrm{C}_{2} \mathrm{~S}}^{\text {hydr }}\left(c_{\mathrm{C}_{2} \mathrm{~S}}\right)^{p_{\mathrm{C}_{2} \mathrm{~S}}} \quad \text { and } \quad f_{\mathrm{C}_{3} \mathrm{~S}}^{\text {hydr }}:=C_{\mathrm{C}_{3} \mathrm{~S}}^{\text {hydr }}\left(c_{\mathrm{C}_{3} \mathrm{~S}}\right)^{p_{\mathrm{C}_{3} \mathrm{~S}}},
$$

where $C_{j}^{\text {hydr }}:=k_{j}^{\text {hydr }} /\left(c_{j}^{0}\right)^{p_{j}-1}$, for $j \in\left\{\mathrm{C}_{2} \mathrm{~S}, \mathrm{C}_{3} \mathrm{~S}\right\}$. Here, $c_{j}^{0}$ denotes the initial concentration of species $j$, while the factor $k_{j}^{\text {hydr }}$ is the reaction constant for the (hydration) reaction between constituent $j$ and water. The exponents $p_{j}$ are the partial reaction orders of species $j$ with respect to the hydration reaction. Referring to [7], we choose $p_{\mathrm{C}_{2} \mathrm{~S}}=3.10, p_{\mathrm{C}_{3} \mathrm{~S}}=2.65$.

Following the approach in $[8,28]$, the reaction rate of the dominant carbonation reaction (2.3) is defined as

$$
f_{\mathrm{Ca}(\mathrm{OH})_{2}}^{\mathrm{reac}}:=C_{\mathrm{Ca}(\mathrm{OH})_{2}}^{\mathrm{rea}} f^{\text {hum }}(\mathrm{RH}) c_{\mathrm{CO}_{2}} c_{\mathrm{Ca}(\mathrm{OH})_{2}},
$$

where $C_{\mathrm{Ca}(\mathrm{OH})_{2}}^{\mathrm{rea}}$ is the reaction constant. The factor $f^{\text {hum }}(\mathrm{RH})$ describes the dependence of the reaction on the relative humidity $\mathrm{RH}$ and is defined as

$$
f^{\text {hum }}(\mathrm{RH}):= \begin{cases}0, & \mathrm{RH} \leq 0.5 \\ 5 / 2(\mathrm{RH}-0.5), & 0.5<\mathrm{RH} \leq 0.9 \\ 1, & \mathrm{RH}>0.9\end{cases}
$$

To point out the structure of the carbonation-reaction rates associated with (2.4)-(2.6), we adopt some modelling ideas in [7]. For $j \in\left\{\mathrm{CSH}, \mathrm{C}_{2} \mathrm{~S}, \mathrm{C}_{3} \mathrm{~S}\right\}$, we assume the production terms by carbonation to be

$$
f_{j}^{\text {reac }}:=C_{j}^{\text {reac }} \Theta\left(c_{j}\right) c_{\mathrm{CO}_{2}},
$$

where $C_{j}^{\text {reac }}:=k_{j}^{\text {reac }} a_{j}^{\mathrm{s}}$ and $k_{j}^{\text {reac }}$ is the reaction constant for the reaction between the constituent $j$ and $\mathrm{CO}_{2}(a q)$. The factor $a_{j}^{\mathrm{s}}$ represents the liquidexposed surface area of constituent $j$, which we assume constant. The factor $\Theta: \mathbb{R} \rightarrow\{0,1\}$ is the Heaviside function $(\Theta(u)=1$, if $u>0$, and $\Theta(u)=0$, if $u \leq 0)$. This modification ensures that the reaction can only take place if the corresponding reactant is available. There is some uncertainty about the ratio of the constants of reactions (2.3) and (2.4). Only a lower estimate can be found in the literature, namely $\frac{k_{j}^{\text {reac }}}{k_{\mathrm{Ca}(\mathrm{OH})_{2}}^{\text {reac }}}>2.4 \cdot 10^{-3}$ (cf. [7]). For the simulations, we select a value for $k_{j}^{\text {reac }}$ such that the latter estimate is satisfied. Then, we point out the effect of varying $k_{j}^{\text {reac }}$ on the penetration depth.

The interfacial mass transfer from pore air to pore water is assumed to be governed by Henry's law [29]. The exchange term is supposed to have the 
Table 1

\begin{tabular}{c||c|c|c|c|c|c|c} 
Species $j$ & $\mathrm{CO}_{2}$ & $\mathrm{Ca}(\mathrm{OH})_{2}$ & $\mathrm{H}_{2} \mathrm{O}$ & $\mathrm{CaCO}_{3}$ & $\mathrm{CSH}$ & $\mathrm{C}_{2} \mathrm{~S}$ & $\mathrm{C}_{3} \mathrm{~S}$ \\
\hline$m_{j} /(\mathrm{g} / \mathrm{mol})$ & 44 & 74 & 18 & 100 & 342 & 228 & 172
\end{tabular}

Molar masses of the active species, cf. [30].

form

$$
f^{\text {Henry }}:=C^{\text {ex }}\left(C^{\text {Henry }} c_{\mathrm{CO}_{2}(g)}-c_{\mathrm{CO}_{2}}\right),
$$

where $C^{\text {ex }}$ is the interfacial mass-transfer coefficient and $C^{\text {Henry }}$ represents the dimensionless Henry constant.

We implicitly assume instantaneous dissolution and precipitation of the other carbonation reactants and products. Moreover, we assume no-flux boundary conditions for the concentrations of all diffusing species (i.e. for $c_{\mathrm{CO}_{2}(g)}, c_{\mathrm{CO}_{2}}$ and $\left.c_{\mathrm{Ca}(\mathrm{OH})_{2}}\right)$ at the interior boundary $\Gamma^{\mathrm{N}}$. At the exterior boundary, $\Gamma^{\mathrm{R}}$, Robin boundary conditions are imposed for $c_{\mathrm{CO}_{2}(g)}$ while no-flux conditions are applied for all other diffusing species. The flux of $c_{\mathrm{CO}_{2}(g)}$ across the exterior boundary is expressed as

$$
f_{\mathrm{CO}_{2}(g)}^{\mathrm{Rob}}:=C_{\mathrm{CO}_{2}(g)}^{\mathrm{Rob}}\left(c_{\mathrm{CO}_{2}(g)}-c_{\mathrm{CO}_{2}(g)}^{\mathrm{ext}}\right),
$$

where the constant $C_{\mathrm{CO}_{2}(g)}^{\mathrm{Rob}}$ represents the mass-transfer coefficient at the external boundary and $c_{\mathrm{CO}_{2}(g)}^{\text {ext }}$ is the given exterior concentration of $\mathrm{CO}_{2}$.

\subsection{Mass balances}

We formulate the macroscopic mass balances for $\mathrm{CO}_{2}$ in both phases (gaseous and liquid) and for $\mathrm{Ca}(\mathrm{OH})_{2}, \mathrm{CaCO}_{3}, \mathrm{CSH}, \mathrm{C}_{2} \mathrm{~S}$ and $\mathrm{C}_{3} \mathrm{~S}$ in the liquid phase. The fact that the latter species should actually be associated with the solid matrix is taken care of via the structure of the reaction-rate constants.

We formulate the system of reaction-diffusion equations independent of the space dimension. In the formulation of the mass balances, we make use of some additional notation, namely $m_{j}$ (the molar mass of species $j$; see table 1), $D_{j}$ (the effective diffusivity of species $j$, i.e. the product of pore diffusivity and tortuosity) and $\nu$ (the outer normal unit vector at the boundary of $\Omega$ ). Based on the discussion above, the complete model can be formulated in the following manner: For $x \in \Omega$ and $t>0$, we have the mass balances

$$
\begin{gathered}
\partial_{t}\left(\phi \phi^{\mathrm{a}} c_{\mathrm{CO}_{2}(g)}(x, t)\right)-\nabla \cdot\left(D_{\mathrm{CO}_{2}(g)} \phi \phi^{\mathrm{a}} \nabla c_{\mathrm{CO}_{2}(g)}\right)=-f^{\mathrm{Henry}}, \\
\partial_{t}\left(\phi \phi^{\mathrm{w}} c_{\mathrm{CO}_{2}}(x, t)\right)-\nabla \cdot\left(D_{\mathrm{CO}_{2}} \phi \phi^{\mathrm{w}} \nabla c_{\mathrm{CO}_{2}}\right) \\
=f^{\mathrm{Henry}}+m_{\mathrm{CO}_{2}} \phi \phi^{\mathrm{w}}\left(-f_{\mathrm{Ca}(\mathrm{OH})_{2}}^{\mathrm{reac}}-3 f_{\mathrm{CSH}}^{\mathrm{reac}}-2 f_{\mathrm{C}_{2} \mathrm{~S}}^{\mathrm{reac}}-3 f_{\mathrm{C}_{2} \mathrm{~S}}^{\mathrm{reac}}\right), \\
\partial_{t}\left(\phi \phi^{\mathrm{w}} c_{\mathrm{Ca}(\mathrm{OH})_{2}}(x, t)\right)-\nabla \cdot\left(D_{\mathrm{Ca}(\mathrm{OH})_{2}} \phi \phi^{\mathrm{w}} \nabla c_{\mathrm{Ca}(\mathrm{OH})_{2}}\right) \\
=m_{\mathrm{Ca}(\mathrm{OH})_{2}} \phi \phi^{\mathrm{w}}\left(-f_{\mathrm{Ca}(\mathrm{OH})_{2}}^{\mathrm{reac}}+\frac{1}{2} f_{\mathrm{C}_{2} \mathrm{~S}}^{\mathrm{hydr}}+\frac{3}{2} f_{\mathrm{C}_{3} \mathrm{~S}}^{\mathrm{hydr}}\right),
\end{gathered}
$$




$$
\begin{gathered}
\partial_{t}\left(\phi \phi^{\mathrm{w}} c_{\mathrm{CaCO}_{3}}^{\mathrm{w}}(x, t)\right)=m_{\mathrm{CaCO}_{3}} \phi \phi^{\mathrm{w}}\left(f_{\mathrm{Ca}(\mathrm{OH})_{2}}^{\mathrm{reac}}+3 f_{\mathrm{CSH}}^{\mathrm{reac}}+2 f_{\mathrm{C}_{2} \mathrm{~S}}^{\mathrm{reac}}+3 f_{\mathrm{C}_{3} \mathrm{~S}}^{\mathrm{reac}}\right) \\
\partial_{t}\left(\phi \phi^{\mathrm{w}} c_{\mathrm{CSH}}^{\mathrm{w}}(x, t)\right)=m_{\mathrm{CSH}} \phi \phi^{\mathrm{w}}\left(-f_{\mathrm{CSH}}^{\mathrm{reac}}+\frac{1}{2} f_{\mathrm{C}_{2} \mathrm{~S}}^{\mathrm{hydr}}+\frac{1}{2} f_{\mathrm{C}_{3} \mathrm{~S}}^{\mathrm{hydr}}\right) \\
\partial_{t}\left(\phi \phi^{\mathrm{w}} c_{\mathrm{C}_{2} \mathrm{~S}}^{\mathrm{w}}(x, t)\right)=m_{\mathrm{C}_{2} \mathrm{~S}} \phi \phi^{\mathrm{w}}\left(-f_{\mathrm{C}_{2} \mathrm{~S}}^{\mathrm{reac}}-f_{\mathrm{C}_{2} \mathrm{~S}}^{\mathrm{hydr}}\right) \\
\partial_{t}\left(\phi \phi^{\mathrm{w}} c_{\mathrm{C}_{3} \mathrm{~S}}^{\mathrm{w}}(x, t)\right)=m_{\mathrm{C}_{3} \mathrm{~S}} \phi \phi^{\mathrm{w}}\left(-f_{\mathrm{C}_{3} \mathrm{~S}}^{\mathrm{reac}}-f_{\mathrm{C}_{3} \mathrm{~S}}^{\mathrm{hydr}}\right)
\end{gathered}
$$

The system is completed by initial conditions,

$$
c_{j}(x, 0)=c_{j}^{0}, \quad x \in \Omega,
$$

as well as no-flux conditions at $\Gamma^{\mathrm{R}}$ and $\Gamma^{\mathrm{N}}$ for all diffusing species except for $c_{\mathrm{CO}_{2}(g)}$, where we prescribe a Robin condition at $\Gamma^{\mathrm{R}}$,

$$
-\left(D_{\mathrm{CO}_{2}(g)} \phi \phi^{\mathrm{a}} \nabla c_{\mathrm{CO}_{2}(g)}(x, t)\right) \cdot \nu=f_{\mathrm{CO}_{2}(g)}^{\mathrm{Rob}}, \quad x \in \Gamma^{\mathrm{R}}, t>0 .
$$

For consistency, we formally included the factors $\phi \phi^{\mathrm{w}}$ in $(3.7 \mathrm{e})-(3.7 \mathrm{~g})$. It is worth noting that the formulation (3.7) remains valid if the porosity $\phi$ and the air- and water-fractions, $\phi^{\mathrm{a}}$ and $\phi^{\mathrm{w}}$, depend on space or time. Moreover, the cement chemistry and the ambient conditions are described by (3.7h) and (3.7i).

\section{Dimensional analysis}

The full system (3.7) is transformed into a dimensionless version (for dimensional analyses of related problems, cf. [19, 7, 6, 29]). In order to obtain a proper scaling of the concentrations, we define maximal concentrations. If diffusion in water is considered sufficiently slow compared to diffusion in air, then, taking into account the stoichiometry of the involved reactions, it follows that the following constants are upper bounds for the corresponding concentrations:

$$
\begin{aligned}
c_{1}^{\mathrm{m}} & :=\phi \phi^{\mathrm{a}} c_{\mathrm{CO}_{2}(g)}^{\mathrm{ext}}, \quad c_{2}^{\mathrm{m}}:=\phi \phi^{\mathrm{w}} C^{\mathrm{Henry}} c_{\mathrm{CO}_{2}(g)}^{\text {ext }}, \\
c_{3}^{\mathrm{m}} & :=\phi \phi^{\mathrm{w}} c_{\mathrm{Ca}(\mathrm{OH})_{2}}^{0}+\frac{1}{2} \frac{m_{\mathrm{Ca}(\mathrm{OH})_{2}}}{m_{\mathrm{C}_{2} \mathrm{~S}}} \phi \phi^{\mathrm{w}} c_{\mathrm{C}_{2} \mathrm{~S}}^{0}+\frac{3}{2} \frac{m_{\mathrm{Ca}(\mathrm{OH})_{2}}}{m_{\mathrm{C}_{3} \mathrm{~S}}} \phi \phi^{\mathrm{w}} c_{\mathrm{C}_{3} \mathrm{~S}}^{0}, \\
c_{6}^{\mathrm{m}} & :=\phi \phi^{\mathrm{w}} c_{\mathrm{CSH}}^{0}+\frac{1}{2} \frac{m_{\mathrm{CSH}}}{m_{\mathrm{C}_{2} \mathrm{~S}}} \phi \phi^{\mathrm{w}} c_{\mathrm{C}_{2} \mathrm{~S}}^{0}+\frac{1}{2} \frac{m_{\mathrm{CSH}}}{m_{\mathrm{C}_{3} \mathrm{~S}}} \phi \phi^{\mathrm{w}} c_{\mathrm{C}_{3} \mathrm{~S}}^{0}, \\
c_{7}^{\mathrm{m}} & :=\phi \phi^{\mathrm{w}} c_{\mathrm{C}_{2} \mathrm{~S}}^{0}, \quad \quad c_{8}^{\mathrm{m}}:=\phi \phi^{\mathrm{w}} c_{\mathrm{C}_{3} \mathrm{~S}}^{0} .
\end{aligned}
$$

The characteristic diffusion time for $\mathrm{CO}_{2}(g)$, which is the fastest species involved, is

$$
T:=L^{2} / D_{\mathrm{CO}_{2}(g)}
$$


We also introduce the following dimensionless quantities

$$
\begin{array}{lll}
u_{1}:=\phi \phi^{\mathrm{a}} c_{\left.\mathrm{CO}_{2}(g)\right)} / c_{1}^{\mathrm{m}}, & u_{2}:=\phi \phi^{\mathrm{w}} c_{\mathrm{CO}_{2}} / c_{2}^{\mathrm{m}}, & u_{3}:=\phi \phi^{\mathrm{w}} c_{\mathrm{Ca}(\mathrm{OH})_{2}} / c_{3}^{\mathrm{m}}, \\
u_{5}:=\phi \phi^{\mathrm{w}} c_{\mathrm{CaCO}_{3}} / c_{5}^{\mathrm{m}}, & u_{6}:=\phi \phi^{\mathrm{w}} c_{\mathrm{CSH}} / c_{6}^{\mathrm{m}}, & u_{7}:=\phi \phi^{\mathrm{w}} c_{\mathrm{C}_{2} \mathrm{~S}} / c_{7}^{\mathrm{m}}, \\
u_{8}:=\phi \phi^{\mathrm{w}} c_{\mathrm{C}_{3} \mathrm{~S}} / c_{8}^{\mathrm{m}}, & &
\end{array}
$$

depending on the dimensionless time and space coordinates $\tilde{t}:=t / T$ and $\tilde{x}:=x / L$. The rapidness of each of the several reactions is then determined by the following dimensionless combinations,

$$
\begin{aligned}
\Phi^{2} & \left.:=\frac{L^{2} m_{\mathrm{CO}_{2}}\left(c_{2}^{\mathrm{m}}\right)\left(c_{3}^{\mathrm{m}}\right)}{D_{\mathrm{CO}_{2}(g)} c_{1}^{\mathrm{m}}} C_{\mathrm{Ca}(\mathrm{OH})_{2}}^{\mathrm{reac}} \quad \text { (Thiele modulus }\right), \\
R_{6} & :=\frac{L^{2} m_{\mathrm{CO}_{2}} c_{2}^{\mathrm{m}}}{D_{\mathrm{CO}_{2}(g)} c_{1}^{\mathrm{m}}} C_{\mathrm{CSH}}^{\mathrm{reac}}, \quad R_{7}:=\frac{L^{2} m_{\mathrm{CO}_{2}} c_{2}^{\mathrm{m}}}{D_{\mathrm{CO}_{2}(g)} c_{1}^{\mathrm{m}}} C_{\mathrm{C}_{2} \mathrm{~S}}^{\mathrm{reac}}, \quad R_{8}:=\frac{L^{2} m_{\mathrm{CO}_{2}} c_{2}^{\mathrm{m}}}{D_{\mathrm{CO}_{2}(g)} c_{1}^{\mathrm{m}}} C_{\mathrm{C}_{3} \mathrm{~S}}^{\mathrm{reac}}, \\
H_{7} & :=\frac{L^{2} m_{\mathrm{CO}_{2}}\left(c_{7}^{\mathrm{m}}\right)^{p_{\mathrm{C}_{2} \mathrm{~S}}}}{D_{\mathrm{CO}_{2}(g)} c_{1}^{\mathrm{m}}} C_{\mathrm{C}_{2} \mathrm{~S}}^{\mathrm{hydr}}, \quad H_{8}:=\frac{L^{2} m_{\mathrm{CO}_{2}}\left(c_{8}^{\mathrm{m}}\right)^{p_{\mathrm{C}_{3} \mathrm{~S}}}}{D_{\mathrm{CO}_{2}(g)} c_{1}^{\mathrm{m}}} C_{\mathrm{C}_{3} \mathrm{~S}}^{\mathrm{hydr}} .
\end{aligned}
$$

The Thiele modulus $\Phi^{2}$ (for specific details, see chapter 4 of [29], e.g.) refers to the main carbonation reaction of $\mathrm{Ca}(\mathrm{OH})_{2}$. The characteristic time of the carbonation reaction of $\mathrm{Ca}(\mathrm{OH})_{2}$ is essentially shorter than the characteristic times of the carbonation reactions of the other species and of the hydration reactions. Based on data from [7], we have $\Phi^{2} \approx 860, R_{6} \approx 6, R_{7} \approx 4, R_{8} \approx 3$, $H_{7} \approx 4 \cdot 10^{-4}$ and $H_{8} \approx 2 \cdot 10^{-4}$. Moreover, the characteristic diffusion time of $\mathrm{CO}_{2}(\mathrm{~g})$ is by a factor of $10^{-6}$ smaller than those of all other species.

The dimensionless production terms are

$$
\begin{aligned}
\eta_{3}^{\text {reac }} & :=\Phi^{2}\left(\phi \phi_{w}\right)^{1-p-q} \eta^{\text {hum }}(\mathrm{RH}) u_{2}^{p} u_{3}^{q}, \\
\eta_{6}^{\text {reac }} & :=3 R_{6} \Theta\left(u_{6}\right) u_{2}, \quad \eta_{7}^{\text {reac }}:=2 R_{7} \Theta\left(u_{7}\right) u_{2}, \quad \eta_{8}^{\text {reac }}:=3 R_{8} \Theta\left(u_{8}\right) u_{2}, \\
\eta_{j}^{\text {hydr }} & :=H_{j}\left(\phi \phi_{w}\right)^{1-p_{j}} u_{j}^{p_{j}}, \quad j=7,8 .
\end{aligned}
$$

We also refer to the report [20] for further details.

The position of the carbonation-reaction front (referring to carbonation of $\left.\mathrm{Ca}(\mathrm{OH})_{2}\right)$ is defined by an isoline of the $\mathrm{Ca}(\mathrm{OH})_{2}$-concentrations, $u_{3}$, namely

$$
s(t):=\left\{x \in \Omega \mid u_{3}(x, t)=0.1\right\}, \quad t>0 .
$$

Definition (4.5) has been suggested in [4] and is motivated by its connection with the change in the $\mathrm{pH}$ value which is measured in experiments. Note that in [19], an alternative definition of the front is given which is based on an isoline of the $\mathrm{CaCO}_{3}$ concentration $u_{5}$. In the simplified model considered in [19], only reaction (1.1) was taken into account, and, therefore, both definitions are equivalent as long as the diffusion of $\mathrm{Ca}(\mathrm{OH})_{2}$ is considered sufficiently slow. Since, in the present setting, $\mathrm{CaCO}_{3}$ is also produced by other reactions, its concentration profile cannot serve as a proper indicator for the carbonation 
progress. For related issues and other definitions of the position of the carbonation front, see also the moving-boundary approaches in $[31,6]$. In particular, in the latter reference, the position of the carbonation front is defined via a dynamic non-local law and its speed is proportional to the carbonation-reaction rate.

\section{Simulation results}

\subsection{Implementation details}

We consider a part of a concrete sample of width $L=3 \mathrm{~cm}$ (1d-situation). We solve the system (3.7) numerically in one space-dimension on the interval $(0, L)$ by the finite element method. This is accomplished by first deriving an appropriate weak formulation of the system and then employing a semidiscretisation in space on a uniform mesh of width $h=1 /(n-1)$ by the Galerkin method together with a standard mass-lumping scheme. For the test and trial functions, first-order splines are used. The nonlinear terms $f_{j}^{\text {reac }}$ and $f_{k}^{\text {hydr }}$ are approximated by the trapezoidal rule. The resulting stiff system of $8 n$ ordinary differential equations is numerically integrated using the MATLAB solver ode15s which is a variable-order solver for stiff equations based on numerical-differentiation formulas. The simulations in this section are obtained having chosen $n=80$.

\subsection{Simulation setting and general results}

As in [19], we simulate an accelerated carbonation test based on data from [7]. In the carbonation experiment described in [7], an OPC sample with water-tocement ratio $R_{\mathrm{w} / \mathrm{c}}=0.50$ is exposed to $50 \% \mathrm{CO}_{2}(\mathrm{~g}), \mathrm{RH}=65 \%$ and $\vartheta=30^{\circ} \mathrm{C}$ in the carbonation chamber. As discussed in section 3.1, we assume a constant concrete porosity in the late stage of hydration considered here. It is given by $\phi=0.22$ and we have $\phi^{\mathrm{a}}=0.85$ and $\phi^{\mathrm{w}}=0.15$. The initial values of the carbonating species are given in table 2 and the reaction constants are listed in table 3 . The diffusivity of $\mathrm{CO}_{2}(g)$ is given by $D_{\mathrm{CO}_{2}(g)}=20 \mathrm{~cm}^{2} /$ d. Typical values of the remaining parameters can be found in [19].

Table 2

\begin{tabular}{c||c|c|c|c} 
Species $\nu$ & $\mathrm{Ca}(\mathrm{OH})_{2}$ & $\mathrm{CSH}$ & $\mathrm{C}_{2} \mathrm{~S}$ & $\mathrm{C}_{3} \mathrm{~S}$ \\
\hline$\phi \phi^{\mathrm{w}} c_{\nu}^{0} /\left(\mathrm{g} / \mathrm{cm}^{3}\right)$ & 0.077 & 0.043 & 0.0047 & 0.0015
\end{tabular}

Initial values of the carbonating species (cf. $[7,19])$. 


\begin{tabular}{|c|c|c|c|c|c|c|}
\hline Parameter & $C_{\mathrm{Ca}(\mathrm{OH})_{2}}^{\mathrm{reac}}$ & $C_{\mathrm{CSH}}^{\mathrm{reac}}$ & $C_{\mathrm{C}_{2} \mathrm{~S}}^{\mathrm{reac}}$ & $C_{\mathrm{C}_{3} \mathrm{~S}}^{\mathrm{reac}}$ & $C_{\mathrm{C}_{2} \mathrm{~S}}^{\mathrm{hydr}}$ & $C_{\mathrm{C}_{3} \mathrm{~S}}^{\mathrm{hydr}}$ \\
\hline Unit & $\frac{\mathrm{cm}^{3}}{\mathrm{~g}^{2} \mathrm{~d}}$ & $\frac{\mathrm{cm}^{3}}{\mathrm{gd}}$ & $\frac{\mathrm{cm}^{3}}{\mathrm{gd}}$ & $\frac{\mathrm{cm}^{3}}{\mathrm{gd}}$ & $\frac{\mathrm{cm}^{3}}{\mathrm{~g}^{p} \mathrm{C}_{2} \mathrm{~S}}$ & $\frac{\mathrm{cm}^{3}}{\mathrm{~g}^{p} \mathrm{C}_{3} \mathrm{~s}}$ \\
\hline Value & 1200 & 2.03 & 1.45 & 1.16 & 0.014 & 0.043 \\
\hline
\end{tabular}

Table 3

Numerical values of the reaction constants (cf. $[7,19])$.
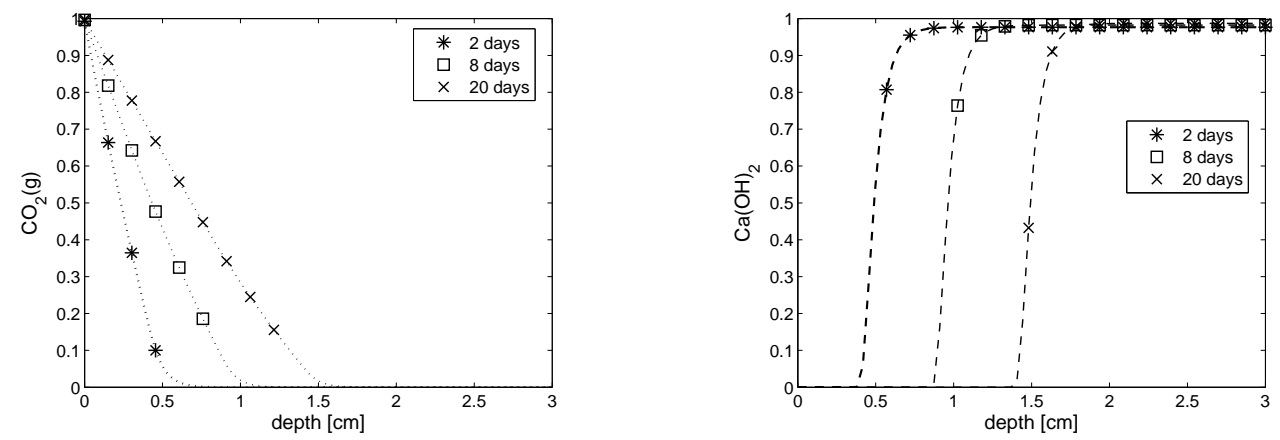

Fig. 2. Concentration profiles of $\mathrm{CO}_{2}(g)$ (left) and $\mathrm{Ca}(\mathrm{OH})_{2}$ (right) obtained with the standard set of parameters of the accelerated test.

Compared to the simulation results of the simplified model [19], the results differ only marginally. In figure 2 , we show the dimensionless concentration profiles of $\mathrm{CO}_{2}(\mathrm{~g})$ and $\mathrm{Ca}(\mathrm{OH})_{2}$. Due to the fast carbonation reaction of $\mathrm{Ca}(\mathrm{OH})_{2}$, there is a sharp decrease in its concentration profile. The concentration profile of $\mathrm{CO}_{2}(g)$ is not as sharp since $\mathrm{CO}_{2}(g)$ needs some time to get to the reaction zone. We note that the profile of $\mathrm{CO}_{2}(a q)$ is quite similar to that of $\mathrm{CO}_{2}(g)$ due to the fast exchange between the air and water phases. Moreover, the additional profiles of the concentrations of $\mathrm{CSH}, \mathrm{C}_{2} \mathrm{~S}$ and $\mathrm{C}_{3} \mathrm{~S}$ (not plotted here) show a similar behaviour to that of $\mathrm{Ca}(\mathrm{OH})_{2}$. It can be observed that due to the hydration reactions, the concentrations of $\mathrm{C}_{2} \mathrm{~S}$ and $\mathrm{C}_{3} \mathrm{~S}$ also decrease in the uncarbonated part of the concrete sample, while those of $\mathrm{CaCO}_{3}$ and $\mathrm{CSH}$ increase. However, these effects are comparably small.

Since an extensive study of the effects due to variations of some of the relevant parameters was performed for the simplified model in [19] (where $\mathrm{CSH}, \mathrm{C}_{2} \mathrm{~S}$ and $\mathrm{C}_{3} \mathrm{~S}$ are neglected), we concentrate here only on effects due the additional phases. First, we compare the influence of each carbonation reaction on the penetration depth (cf. section 5.3). We then investigate the influence of each carbonation reaction, in particular the consumption of $\mathrm{CO}_{2}$ by each reaction and the alternate neglect of $\mathrm{CSH}, \mathrm{C}_{2} \mathrm{~S}$ and $\mathrm{C}_{3} \mathrm{~S}$ (cf. section 5.4) as well as the effects due to a variation of the carbonation- and hydration-rate constants (cf. section 5.5). The influence of the amount of additional constituents available to carbonation is considered in section 5.6. 

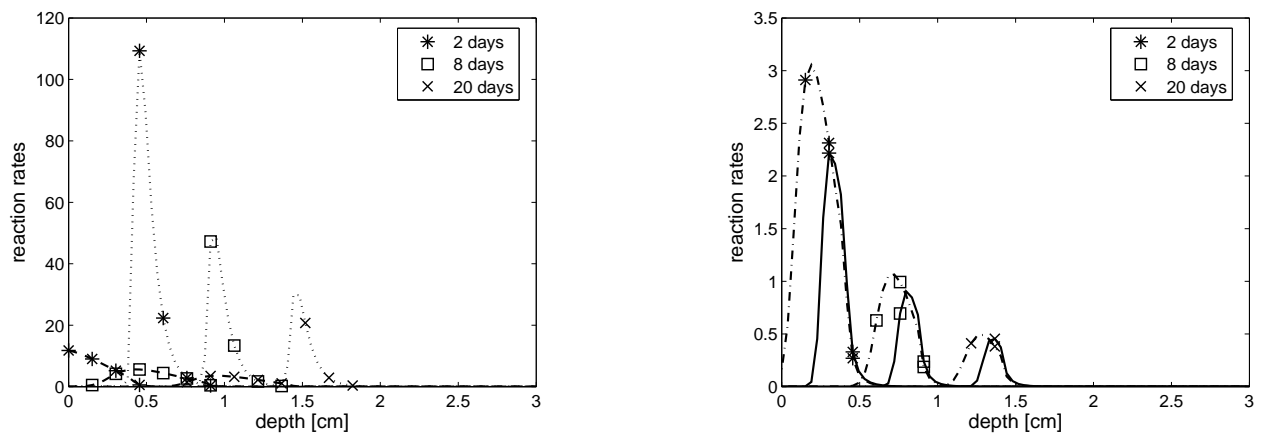

Fig. 3. Dimensionless production terms $\eta_{j}^{\text {reac }}$ of the different carbonation reactions. Left: Reaction of $\mathrm{Ca}(\mathrm{OH})_{2}(j=3$, dotted $)$ and reaction of CSH $(j=6$, dashed). Right: Reaction of $\mathrm{C}_{2} \mathrm{~S}(j=7$, dash-dotted $)$ and $\mathrm{C}_{3} \mathrm{~S}(j=8$, solid $)$.

\subsection{Competition of parallel carbonation reactions}

We first compare the influence of each carbonation reaction on the penetration depth. In figure 3 , the dimensionless production terms $\eta_{j}^{\text {reac }}, j=3,6,7,8$, are plotted. It can be observed that the strongest carbonation reaction is that of $\mathrm{Ca}(\mathrm{OH})_{2}$, followed by that of $\mathrm{CSH}$. The reaction strengths associated with $\mathrm{C}_{2} \mathrm{~S}$ and $\mathrm{C}_{3} \mathrm{~S}$ are essentially smaller. The reaction zone associated with $\mathrm{Ca}(\mathrm{OH})_{2}{ }^{-}$ depletion is the most narrow and furthest advanced into the concrete sample at any given time. On the other hand, the reaction zone of $\mathrm{CSH}$ is the widest and also lagging behind the most. The width of the reaction zone associated with $\mathrm{C}_{2} \mathrm{~S}$ is somewhere in between, while that related to $\mathrm{C}_{3} \mathrm{~S}$ is quite similar to that of $\mathrm{Ca}(\mathrm{OH})_{2}$ (apart from the magnitude of the reaction rate). This last effect can be explained by the comparably small amount of $\mathrm{C}_{3} \mathrm{~S}$ available to carbonation.

Since we expect a strong competition for $\mathrm{CO}_{2}$ by the carbonation reactions, we are particularly interested in how much $\mathrm{CO}_{2}$ is consumed by each reaction. Under the assumption that $\mathrm{CSH}, \mathrm{C}_{2} \mathrm{~S}$ and $\mathrm{C}_{3} \mathrm{~S}$ cannot diffuse, we can calculate the amount of $\mathrm{CO}_{2}$, which has been consumed by each carbonation reaction, in each point after any given time. The amount of $\mathrm{CO}_{2}$ consumed by carbonation of each reactant is plotted in figure 4. It can be observed that all four species compete for $\mathrm{CO}_{2}$. However, the amount of $\mathrm{CO}_{2}$ consumed by the carbonation of $\mathrm{Ca}(\mathrm{OH})_{2}$ is much greater than that of all other species. Namely, for the chosen set of parameters, the amount consumed by carbonation of $\mathrm{Ca}(\mathrm{OH})_{2}$ is three times as great as that of CSH, 20 times as great as that of $\mathrm{C}_{2} \mathrm{~S}$ and roughly 50 times as great as that of $\mathrm{C}_{3} \mathrm{~S}$. It is also worth noting that the reaction zone associated with $\mathrm{Ca}(\mathrm{OH})_{2}$ is always ahead of the other reaction zones. This fact agrees with the experimental observations in [10]. 

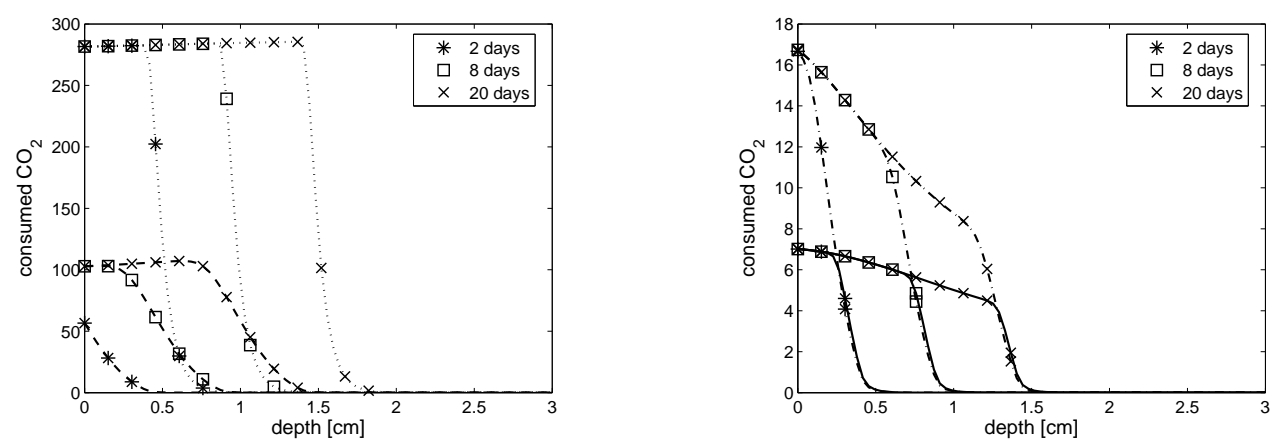

Fig. 4. Concentration of $\mathrm{CO}_{2}$ consumed by the carbonation of the carbonatable species. Left: $\mathrm{CO}_{2}$ consumed by carbonation of $\mathrm{Ca}(\mathrm{OH})_{2}$ (dotted) and $\mathrm{CSH}$ (dashed). Right: $\mathrm{CO}_{2}$ consumed by carbonation of $\mathrm{C}_{2} \mathrm{~S}$ (dash-dotted) and $\mathrm{C}_{3} \mathrm{~S}$ (solid)

\subsection{Influence of each carbonation process on the carbonation depth}

Since other models usually neglect the effect of $\mathrm{CSH}, \mathrm{C}_{2} \mathrm{~S}$ and $\mathrm{C}_{3} \mathrm{~S}$, we are interested in evaluating how great their impact can be on the carbonation of $\mathrm{Ca}(\mathrm{OH})_{2}$. Therefore, we consider two special cases and compare them to the full scenario: in the first case, we neglect $\mathrm{CSH}, \mathrm{C}_{2} \mathrm{~S}$ and $\mathrm{C}_{3} \mathrm{~S}$; in the second case, we neglect $\mathrm{C}_{2} \mathrm{~S}$ and $\mathrm{C}_{3} \mathrm{~S}$. Recall that the carbonation depth $s(t)$ (cf. (4.5)) is defined via an a priori chosen isoline of the concentration profile of $\mathrm{Ca}(\mathrm{OH})_{2}$. Therefore, we consider the amount of produced $\mathrm{CaCO}_{3}$ as well as the carbonation depth in the above two cases. Since $\mathrm{C}_{2} \mathrm{~S}$ and $\mathrm{C}_{3} \mathrm{~S}$ do not consume much $\mathrm{CO}_{2}$ compared to $\mathrm{CSH}$ and $\mathrm{Ca}(\mathrm{OH})_{2}$, it is reasonable to investigate their collective influence on the carbonation. The results obtained neglecting $\mathrm{C}_{2} \mathrm{~S}$ and $\mathrm{C}_{3} \mathrm{~S}$ are compared to those of the full scenario in figure 5. It can be observed that the carbonation of CSH affects the simulated carbonation depth as it consumes $\mathrm{CO}_{2}$ which would otherwise be available for carbonation of $\mathrm{Ca}(\mathrm{OH})_{2}$. The influence of $\mathrm{C}_{2} \mathrm{~S}$ and $\mathrm{C}_{3} \mathrm{~S}$, on the other hand, seems to be negligible.

\subsection{Variation of carbonation- and hydration-rate constants}

As the carbonation- and hydration-rate constants cannot be directly measured [cf. 7, 32, e.g.], we want to illustrate the effects due to their variation. The effect of the variation of the Thiele modulus on the carbonation penetration depth was extensively investigated in [19]. Therefore, we concentrate on the reaction and hydration rates of $\mathrm{CSH}, \mathrm{C}_{2} \mathrm{~S}$ and $\mathrm{C}_{3} \mathrm{~S}$.

In figure 6 , the dimensionless production terms $\eta_{j}^{\text {reac }}$ (defined by (4.4)) are plotted for the standard setting as well as for the cases where the reaction- 

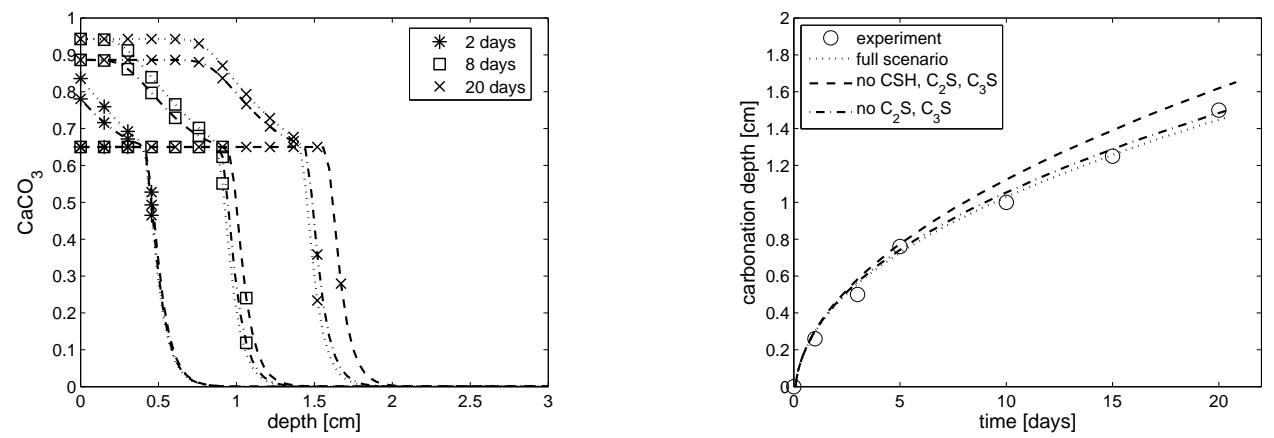

Fig. 5. Profile of $\mathrm{CaCO}_{3}$ (left) and carbonation depth (right) for the full scenario (dotted), if $\mathrm{CSH}, \mathrm{C}_{2} \mathrm{~S}$ and $\mathrm{C}_{3} \mathrm{~S}$ are neglected (dashed), and if $\mathrm{C}_{2} \mathrm{~S}$ and $\mathrm{C}_{3} \mathrm{~S}$ are neglected (dash-dotted). The circles in the right plot denote experimental data from [7].

rate constants of the carbonation of $\mathrm{CSH}, \mathrm{C}_{2} \mathrm{~S}$, and $\mathrm{C}_{3} \mathrm{~S}$ have been chosen 10 times and 100 times greater. For the 10 times greater reaction rates, it can be observed that the carbonation depth is smaller than in the standard setting (cf. fig. 7, right). This is due to the fact that $\mathrm{CO}_{2}$ is consumed by the carbonation of $\mathrm{CSH}, \mathrm{C}_{2} \mathrm{~S}$ and $\mathrm{C}_{3} \mathrm{~S}$ more quickly. Therefore, it is not available for carbonation of $\mathrm{Ca}(\mathrm{OH})_{2}$. Moreover, the concentration profiles of $\mathrm{CSH}, \mathrm{C}_{2} \mathrm{~S}$ and $\mathrm{C}_{3} \mathrm{~S}$ (not shown) appear steeper and it can be seen that, in this setting, all reaction zones almost coincide.

If the carbonation-rate constants of $\mathrm{CSH}, \mathrm{C}_{2} \mathrm{~S}$, and $\mathrm{C}_{3} \mathrm{~S}$ are chosen 100 times greater than in the standard setting, it can be observed that the reaction zones of these additional phases overtake the one associated with $\mathrm{Ca}(\mathrm{OH})_{2}$. Nevertheless, this is due to the fact that there is not as much $\mathrm{CSH}, \mathrm{C}_{2} \mathrm{~S}$ and $\mathrm{C}_{3} \mathrm{~S}$ available for carbonation as there is $\mathrm{Ca}(\mathrm{OH})_{2}$. Therefore, these phases are used up faster and the associated reaction zones advance more quickly. As in the previous setting, the carbonation depth is only slightly affected. Regarding this last observation, recall that $s(t)$, defined by (4.5), does not recover this faster advancement of the reaction zones of the additional phases.

If the reaction-rate constants of $\mathrm{CSH}, \mathrm{C}_{2} \mathrm{~S}$ and $\mathrm{C}_{3} \mathrm{~S}$ are chosen significantly smaller than in the standard setting (multiplying them by a factor of $1 / 10$ or $1 / 100$, e.g.), then the influence of the additional phases just decreases steadily.

In figure 7 , the concentration profile of $\mathrm{CaCO}_{3}$ and the carbonation depth are shown for the three settings considered above, and, as a forth setting, for 10 times faster hydration-rate constants than in the standard setting. The overall hydration process is assumed to be in its final phase. Therefore, it is almost complete at the beginning of our simulations. However, some small competition effects can be observed. The concentration profiles of $\mathrm{C}_{2} \mathrm{~S}$ and $\mathrm{C}_{3} \mathrm{~S}$ (not plotted) show a considerable deviation while the influence on the carbonation depth is rather small. The dotted and solid lines in figure 7 almost 

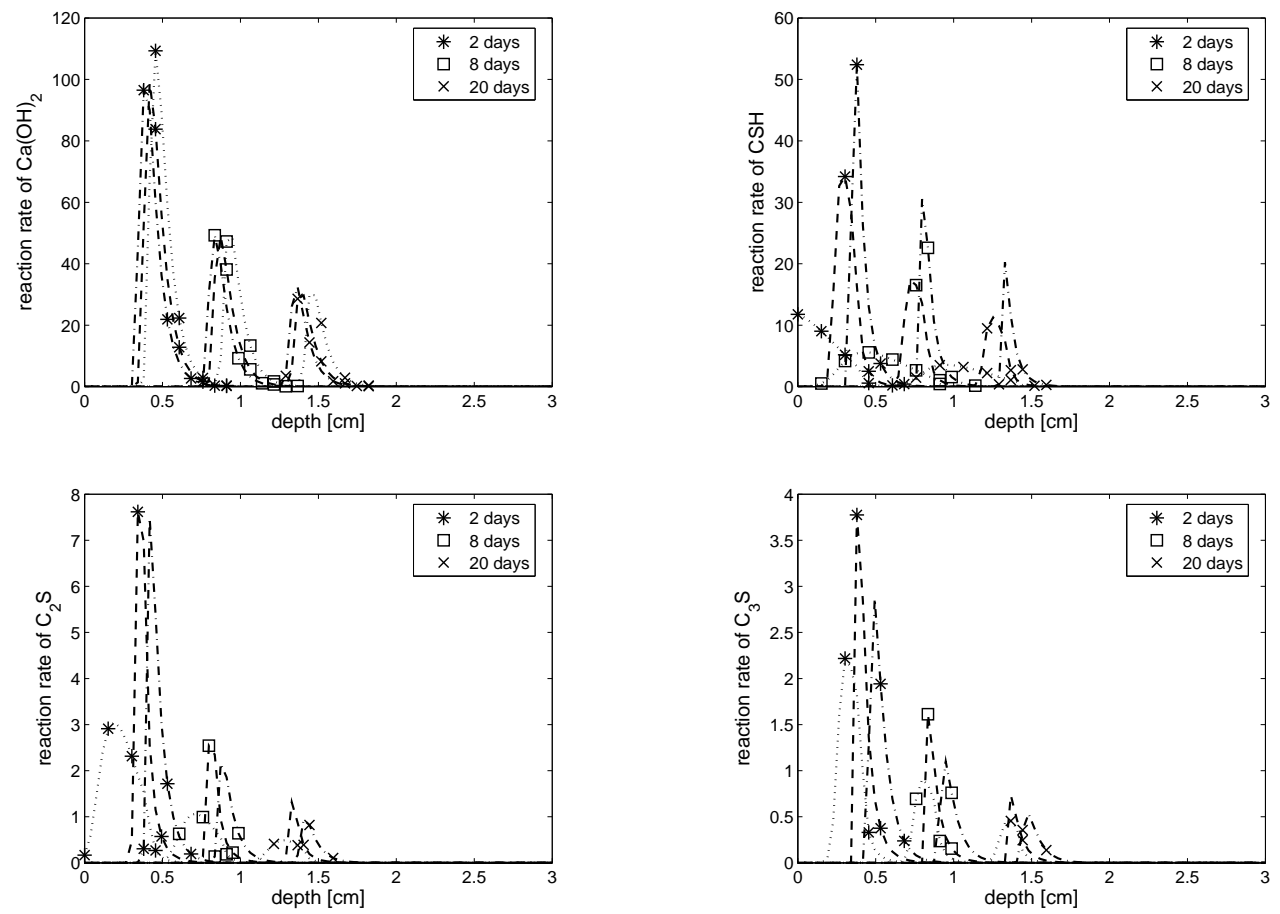

Fig. 6. Production rates obtained with standard carbonation-reaction rates (dotted), rates 10 times faster (dashed) and rates 100 times faster (dash-dotted) than in the standard setting.
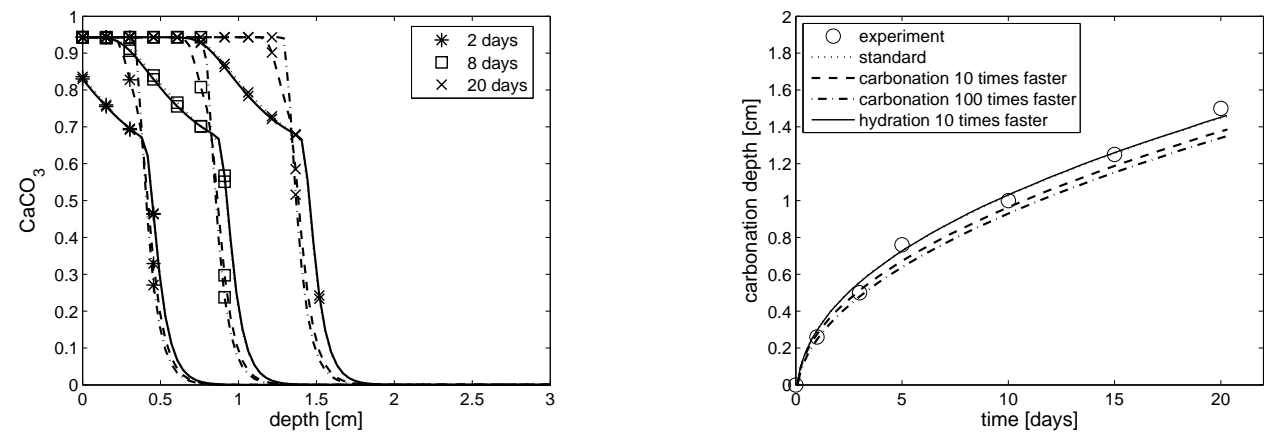

Fig. 7. Concentration profile of $\mathrm{CaCO}_{3}$ (left) as well as carbonation depth (right) obtained with carbonation-reaction rates 10 times faster (dashed) and rates 100 times faster (dash-dotted) than in the standard setting (dotted). The solid line corresponds to 10 times faster hydration-reaction rates than in the standard setting and almost coincides with the output of the latter. The circles in the right plot denote measured penetration depths from [7].

coincide. It is worth mentioning that even a multiplication of the hydrationrate constants by a factor of 1000 does not have a significant effect on the carbonation depth.

In summary, the variations of the hydration-rate constants have virtually no influence on the model output in the late stage of hydration considered here. 

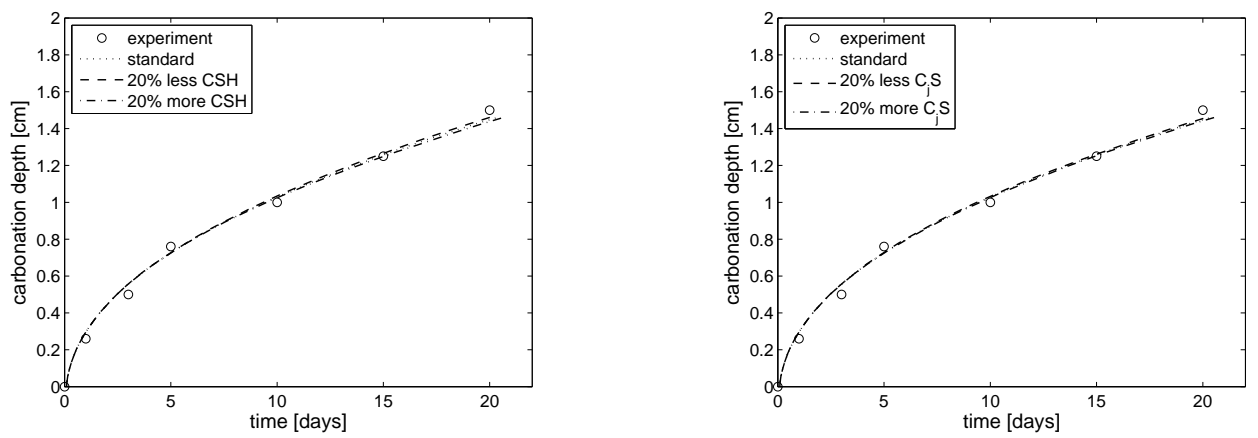

Fig. 8. Carbonation depths obtained with $20 \%$ lower and $20 \%$ higher initial CSH (left) and $\mathrm{C}_{2} \mathrm{~S}$ and $\mathrm{C}_{3} \mathrm{~S}$ (right) concentrations compared to the standard values. The circles denote measured penetration depths from [7].

The variations of the reaction-rate constants of $\mathrm{CSH}, \mathrm{C}_{2} \mathrm{~S}$ and $\mathrm{C}_{3} \mathrm{~S}$ have a small influence.

\subsection{Influence of the amount of available constituents}

In order to investigate the influence of different amounts of carbonatable constituents within the cement paste, we present simulation results for different initial values of $\mathrm{CSH}, \mathrm{C}_{2} \mathrm{~S}$ and $\mathrm{C}_{3} \mathrm{~S}$. The consideration of different initial values of $\mathrm{CSH}$ can also be viewed as considering different $\mathrm{Ca}(\mathrm{OH})_{2}$-to-CSH ratios.

In figure 8 (left), the carbonation depth is plotted for $20 \%$ higher and $20 \%$ lower initial concentration of $\mathrm{CSH}$ and compared to the standard setting. The same results for $20 \%$ higher and lower $\mathrm{C}_{2} \mathrm{~S}$ and $\mathrm{C}_{3} \mathrm{~S}$ initial concentrations are shown in figure 8(right). It can be seen that the influence of such a change on the carbonation depth is small.

\section{Summary and Conclusions}

The mathematical model of concrete carbonation presented in [19] has been extended to take into account several parallel carbonation and hydration reactions. This extended model consists of a coupled nonlinear system of ordinary and partial differential equations describing the mass balances of the active species. To allow easy comparisons of the importance of the involved carbonation and hydration reactions, the system of equations has been transformed into a dimensionless form. Using numerical simulations of an accelerated carbonation test, the influence of each single reaction on the penetration depth has been investigated in detail. Experimental results from [7] were recovered. The following conclusions can be drawn: 
- Compared to the simplified model in [19], which neglects carbonation of the $\mathrm{C}-\mathrm{S}-\mathrm{H}$ phases and of the unhydrated components $\mathrm{C}_{2} \mathrm{~S}$ and $\mathrm{C}_{3} \mathrm{~S}$, the numerical simulations show that the latter two constituents only have a small influence on the total outcome in the late stage of hydration considered here. This effect occurs even if we assume that all of $\mathrm{C}_{2} \mathrm{~S}$ and $\mathrm{C}_{3} \mathrm{~S}$ are completely accessible to their carbonation reactions. Therefore, it seems reasonable to neglect them in carbonation prediction models.

- All involved species compete for carbon dioxide. This competition slows down the carbonation of calcium hydroxide since less carbon dioxide becomes available to carbonation. This effect, causing a reduction of propagation speed of the carbonation layer, was of noticeable extent only for CSH. Under natural conditions, experiments suggest that the influence of the carbonation of C-S-H phases might become even smaller (cf. [10]) because of the worse accessibility of carbon dioxide to $\mathrm{C}-\mathrm{S}-\mathrm{H}$ and the possibly lesser amount of C-S-H available in the concrete (owing to uncomplete hydration, e.g.). On the other hand, for concretes with high C-S-H content, this influence might be stronger yet again.

- For a large range of parameters, we observe that distinct internal layers, where the carbonation reactions are localised, are formed and travel through the material. Each of them can be associated with one specific carbonation reaction. In contrast, the hydration reactions occur fairly uniformly as long as unhydrated constituents are available. Assuming larger hydration reaction constants has virtually no influence on the carbonation depth while larger reaction rate constants associated with the additional species result in small changes of the carbonation depth. An increase or decrease in available additional reactants by $20 \%$ virtually does not affect the carbonation depth. The fact that the reaction layer associated with CSH lags behind that of calcium hydroxide, which was observed experimentally in [10], is recovered in our simulations.

The assumptions of the model need to be revised in order to broaden the range of applicability of the model to atmospheric carbonation, where, in particular, the effect of C-S-H and unhydrated constituents on the penetration depth is not a priori clear. Furthermore, in situations where C-S-H carbonation has a noticable influence, the importance of resulting porosity changes, and hence changes in the diffusivity of $\mathrm{CO}_{2}$, need to be further investigated.

\section{Acknowledgements}

We are grateful to J. Kropp, Institut für Baustofftechnologie, University of Applied Sciences, Bremen, and F. Schmidt-Döhl, Materials Testing Institute, Braunschweig, for helpful comments. M. A. P. would like to acknowledge the financial support of the German National Academic Foundation. A. M. and 
M. B. would like to thank the Deutsche Forschungsgemeinschaft (DFG) for a grant through the special priority program SPP1122 Prediction of the Course of Physicochemical Damage Processes Involving Mineral Materials and S. A. M. acknowledges the funding by the state of Bremen via the PhD program Scientific Computing in Engineering. 


\section{Notation}

\begin{tabular}{|c|c|c|}
\hline Parameter & Unit & Description \\
\hline $\begin{array}{l}R_{\mathrm{w} / \mathrm{c}} \\
\phi \\
\phi^{\mathrm{a}} \\
\phi^{\mathrm{w}}\end{array}$ & $\begin{array}{l}- \\
- \\
- \\
-\end{array}$ & $\begin{array}{l}\text { water-to-cement ratio } \\
\text { concrete porosity } \\
\text { volume fraction of air-filled pores } \\
\text { volume fraction of water-filled pores }\end{array}$ \\
\hline $\begin{array}{l}m_{j} \\
\rho_{j} \\
c_{j} \\
\mathrm{RH} \\
c_{\mathrm{CO}_{2}}^{\mathrm{ex}} \\
c_{j}^{0}\end{array}$ & $\begin{array}{l}\mathrm{g} / \mathrm{mol} \\
\mathrm{g} / \mathrm{cm}^{3} \\
\mathrm{~g} / \mathrm{cm}^{3} \\
- \\
\mathrm{g} / \mathrm{cm}^{3} \\
\mathrm{~g} / \mathrm{cm}^{3}\end{array}$ & $\begin{array}{l}\text { molecular weight of species } j \\
\text { density of species } j \\
\text { mass concentration of species } j \\
\text { relative humidity } \\
\text { ambient concentration of } \mathrm{CO}_{2}(g) \\
\text { initial concentration of species } j\end{array}$ \\
\hline $\begin{array}{l}D_{j} \\
f_{j}^{\text {reac }} \\
f_{j}^{\text {hydr }} \\
f^{\text {Henry }} \\
f_{j}^{\text {Rob }} \\
C_{j}^{\text {reac }} \\
C_{j}^{\text {hydr }} \\
C^{\text {Henry }} \\
C^{\text {ex }} \\
C_{j}^{\text {Rob }} \\
\vartheta \\
L \\
\nu\end{array}$ & $\begin{array}{l}\mathrm{cm}^{2} / \mathrm{d} \\
\mathrm{mol} /\left(\mathrm{cm}^{3} \mathrm{~d}\right) \\
\mathrm{mol} /\left(\mathrm{cm}^{3} \mathrm{~d}\right) \\
\mathrm{g} /\left(\mathrm{cm}^{3} \mathrm{~d}\right) \\
\mathrm{g} /\left(\mathrm{cm}^{2} \mathrm{~d}\right) \\
\\
(\text { see table } 3) \\
\frac{\mathrm{cm}^{3}}{\mathrm{~g}^{p_{j}} \mathrm{~d}} \\
- \\
1 / \mathrm{d} \\
\mathrm{cm} / \mathrm{d} \\
\mathrm{K} \\
\mathrm{cm} \\
-\end{array}$ & $\begin{array}{l}\text { diffusivity of species } j \\
\text { production term by carbonation of species } j \\
\text { production term by hydration of species } j \\
\text { production term by } \mathrm{CO}_{2} \text {-dissolution } \\
\text { production term exchange at the boundary of } \\
\text { species } j \\
\text { carbonation-reaction constant of species } j \\
\text { hydration-reaction constant of species } j \\
\text { dimensionless Henry constant } \\
\text { gas-liquid mass transfer coefficient of } \mathrm{CO}_{2}(g) \\
\text { mass-transfer coefficient of species } j \\
\text { temperature } \\
\text { width of the sample } \\
\text { unit normal vector directed outward }\end{array}$ \\
\hline $\begin{array}{l}T \\
c_{j}^{\mathrm{m}} \\
u_{j} \\
\Phi^{2} \\
\eta_{j}^{\text {reac }} \\
\eta_{j}^{\text {hydr }} \\
s\end{array}$ & $\begin{array}{l}\mathrm{d} \\
\mathrm{g} / \mathrm{cm}^{3} \\
- \\
- \\
-\end{array}$ & $\begin{array}{l}\text { characteristic diffusion time } \\
\text { maximal concentration of species } j \\
\text { dimensionless concentration of species } j \\
\text { Thiele modulus } \\
\text { dimensionless carbonation-reaction rate of } \\
\text { species } j \\
\text { dimensionless hydration-reaction rate of species } i \\
\text { position of the carbonation-reaction front } \\
(\text { cf. }(4.5))\end{array}$ \\
\hline
\end{tabular}




\section{References}

[1] T. A. Bier, Karbonatisierung und Realkalisierung von Zementstein und Beton, Ph.D. thesis, University Fridericiana in Karlsruhe, Schriftenreihe des Instituts für Massivbau und Baustofftechnologie. Editors: J. Eibl, H. K. Hilsdorf (1988).

[2] J. Kropp, Relations between transport characteristics and durability, in: J. Kropp, H. K. Hilsdorf (Eds.), Performance Criteria for Concrete Durability, RILEM Report 12, E and FN Spon Ed., 1995, pp. 97-137.

[3] T. Chaussadent, États de lieux et réflexions sur la carbonatation du beton armé, Tech. rep., Laboratoire Central de Ponts et Chaussées, Paris (1999).

[4] A. Steffens, Modellierung von Karbonatisierung und Chloridbindung zur numerischen Analyse der Korrosionsgefährdung der Betonbewehrung, Ph.D. thesis, Institute for Statics, Technical University Braunschweig (2000).

[5] D. Bunte, Zum Karbonatisierungsbedingten Verlust der Dauerhaftigkeit von Aussenbauteilen aus Stahlbeton, Ph.D. thesis, Technical University of Braunschweig (1994).

[6] A. Muntean, A Moving-Boundary Problem: Modeling, Analysis and Simulation of Concrete Carbonation, Ph.D. thesis, University of Bremen, Cuvillier (2006).

[7] V. G. Papadakis, C. G. Vayenas, M. N. Fardis, A reaction engineering approach to the problem of concrete carbonation, AIChE J. 35 (1989) 1639-1650.

[8] A. Steffens, D. Dinkler, H. Ahrens, Modeling carbonation for corrosion risk prediction of concrete structures, Cem. Concr. Res. 32 (2002) 935941.

[9] K. Sisomphon, Influence of pozzolanic material additions on the development of the alkalinity and the carbonation behaviour of composite cement pastes and concretes, Ph.D. thesis, TU Hamburg-Harburg (2004).

[10] T. Chaussadent, Analyse des mécanismes de carbonatation du beton, in: AFPC-AFREM Durabilite des Betons "Méthodes recommandés pour la mesure des grandeurs associés à la durabilité", INSA Génie Civil, Toulouse, France, 1997, pp. 75-86.

[11] V. Baroghel-Bouny, T. Chaussadent, Transfers within concrete and structural durability. Overview of five years of research and outlook for the future, Bull. Lab. Ponts et Chaussées 248 (2004) 93-111.

[12] H. F. W. Taylor, Cement Chemistry, Thomas Telford Publishing, 1997.

[13] V. I. Babushkin, G. M. Matveyev, O. P. Mchedlov-Petrossyan, Thermodynamics of Silicates, Springer, 1985.

[14] V. S. Ramachandran, Concrete science, in: V. S. Ramachandran, J. J. 
Beaudoin (Eds.), Handbook of Analytical Techniques in Concrete Science and Technology, Noyes Publications, 2001, pp. 1-62.

[15] S. J. Preece, J. Billingham, A. C. King, On the initial stages of cement hydration, J. Engng. Math. 40 (2001) 43-58.

[16] A. Salhan, J. Billingham, A. C. King, The effect of a retarder on the hydration of tricacium silicate, J. Engng. Math. 45 (2003) 367-377.

[17] V. G. Papadakis, C. G. Vayenas, M. N. Fardis, Physicochemical process and mathematical modeling of concrete chlorination, Chem. Eng. Sci. 51 (4) (1996) 505-513.

[18] B. Bary, A. Sellier, Coupled moisture - carbon dioxide - calcium transfer model for carbonation of concrete, Cem. Concr. Res. 34 (2004) 1859-1872.

[19] S. A. Meier, M. A. Peter, A. Muntean, M. Böhm, Dynamics of the internal reaction layer arising during carbonation of concrete, Chem. Engng Sci. 62 (2007) 1125-1137.

[20] M. A. Peter, A. Muntean, S. A. Meier, M. Böhm, Modelling and simulation of concrete carbonation: competition of several carbonation reactions, Berichte aus der Technomathematik 05-03, ZeTeM, University of Bremen (2005).

[21] A. Muntean, M. Böhm, Dynamics of a moving reaction interface in a concrete wall, to appear in: J. F. Rodrigues et al. (Eds.), Free and Moving Boundary Problems. Theory and Applications. Birkhäuser (2006).

[22] S. A. Meier, M. A. Peter, M. Böhm, A two-scale modelling approach to reaction-diffusion processes in porous materials, Comp. Mat. Sci. 39 (2006) 49-54.

[23] M. A. Peter, Homogenisation of a chemical degradation mechanism inducing an evolving microstructure, C. R. Mécanique 335 (11) (2007) 679-684.

[24] J. J. Chen, J. J. Thomas, H. F. W. Taylor, H. M. Jennings, Solubility and structure of calcium silicate hydrate, Cem. Concr. Res. 34 (2004) 1499-1519.

[25] F. Dunstetter, M.-N. de Noirfontaine, M. Courtial, Polymorphism of tricalcium silicate, the major compound of portland cement clinker 1. Structural data: review and unified analysis, Cem. Concr. Res. 36 (1) (2006) 39-53.

[26] D. A. Kulik, M. Kersten, Aqueous solubility diagrams for cementitious waste stabilization systems: II, end-member stoichiometries of ideal calcium silicate hydrate solid solutions, J. American Ceramic Soc. 84 (12) (2001) 3017-3026.

[27] J. Bear, A. Verruijt, Modeling Groundwater Flow and Pollution, D. Reidel Publishing Company, 1987.

[28] A. V. Saetta, B. A. Schrefler, R. V. Vitaliani, The carbonation of concrete 
and the mechanism of moisture, heat and carbon dioxide flow through porous materials, Cem. Concr. Res. 23 (4) (1993) 761-772.

[29] G. F. Froment, K. B. Bischoff, Chemical Reactor Analysis and Design, 2nd Edition, Wiley Series in Chemical Engineering, John Wiley and Sons, 1990.

[30] D. R. Lide (Ed.), CRC Handbook of Chemistry and Physics, 82nd Edition, CRC Press LLC, 2001-2002, a Ready-Reference Book of Chemical and Physical Data.

[31] C. Y. Wen, Noncatalytic heterogeneous solid fluid reaction models, Industr. Engng. Chem. 60 (9) (1968) 34-54.

[32] F. Schmidt-Döhl, Ein Modell zur Berechnung von kombinierten chemischen Reaktions- und Transportprozessen und seine Anwendung auf die Korrosion mineralischer Baustoffe, Tech. Rep. 125, Institut für Baustoffe, Massivbau und Brandschutz, TU Braunschweig (1996). 